\title{
Hubungan Mild Cognitive Impairment (MCI) dengan Hipertensi Menggunakan Mini Mental State Examination (MMSE)
}

\author{
Enny Lestari, ${ }^{1}$ Meiliza Rausan Fikrani, ${ }^{2}$ Esy Maryanti ${ }^{3}$
}

\begin{abstract}
Mild Cognitive Impairment is a decreasing in memory, decision, language and attention with normal functional activity which not classified in dementia. One of risk factor of MCI is high blood pressure or hypertension. Hypertension is $\geq 140 \mathrm{mmHg}$ systolic blood pressure and $\geq 90 \mathrm{mmHg}$ diastolyc blood pressure. The purpose of this research is to informing the relation between mild cognitive impairment and hypertension in Local Women Organization (PKK RW IX Kelurahan Tangkerang Timur Pekanbaru). The research used cross-sectional analitic study method, finished on Januari 2015. Fifty subjects of Local Women Organization (PKK RW IX) were involved in this research, they were divided into two criterias, 31 with MCI and 19 with non MCI. Based on the research, 21 of 31 MCI were detected with hypertension. The Chi Square test showed there is significant relation between MCI and hypertension ( $p$ value $=0,004)$.
\end{abstract}

Keywords: mild cognitive impairment, hypertension, MMSE.

Mild cognitive impairment (MCI) merupakan stadium gangguan kognitif yang melebihi perubahan normal yang terkait dengan penambahan usia (normal expected age related changes), akan tetapi aktivitas fungsional masih normal dan belum memenuhi kriteria demensia. ${ }^{1}$ Mild cognitive impairment merupakan suatu transisi perubahan antara penuaan dengan demensia yang terjadi pada kalangan usia lanjut. ${ }^{2-4}$

Pertemuan Al- zheimer's Association International Conference tahun 2011 menyatakan bahwa prevalensi MCI di 6 negara maju, seperti USA, Australia, Jerman, Inggris, Swiss dan Perancis adalah $15 \%-42 \%$. Prevalensi MCI di negara kawasan Asia mencapai 17,1\%.Menurut Direktorat Jenderal Pelayanan Medik Kementerian Kesehatan tahun 2010, prevalensi MCI pada usia lanjut di Indonesia sekitar 32,4\%. ${ }^{5}$

Beberapa penelitian epidemiologi menyatakan bahwa MCI terjadi terutama karena proses penuaan,

\footnotetext{
1 Penulis untuk korespondensi : Bagian Saraf Fakultas Kedokteran Universitas Riau

2 Fakultas Kedokteran Universitas Riau

3 Bagian Parasitologi Fakultas Kedokteran Universitas Riau
}

namun perkembangan penyakit MCI dapat diakibatkan oleh berbagai faktor, salah satunya risiko kardiovaskuler seperti hipertensi, hiperlipidemia, diabetes dan gangguan jantung termasuk gagal jantung kronik dan aritmia. Faktor lain yang juga berhubungan yaitu penyakit serebrovaskular seperti stroke, trauma otak, infeksi serebral, epilepsi dan tumor otak yang dapat memperburuk fungsi kognitif dan mempercepat terjadinya demensia. ${ }^{6,7}$

Hipertensi adalah tekanan darah sistolik $\geq 140$ mmHg atau tekanan diastolik e $\geq 90$ mmHg. ${ }^{8,9}$ Secara epidemiologi semakin tingginya populasi usia lanjut, maka jumlah pasien dengan hipertensi semakin bertambah. Data dari The National Health and Nutrition Examination Survey (NHNES) menunjukkan bahwa dari tahun 1999-2000 insiden hipertensi pada orang dewasa mencapai $29-31 \%$ yang berarti $58-65$ juta orang mengalami hipertensi di Amerika. ${ }^{10}$ Data dari Riset Kesehatan Dasar (Riskesdas) 2013, menunjukkan prevalensi hipertensi di Indonesia berdasarkan hasil pengukuran pada umur $\geq 18$ tahun sebesar 25,8\%.11 Menurut profil Kesehatan Propinsi Riau tahun 2010 terdapat kasus hipertensi sebesar 20,9\% di provinsi Riau. ${ }^{12}$ 
Penuaan menjadi faktor utama terjadinya gangguan fungsi kognitif ini, tetapi berdasarkan penelitian yang dilakukan oleh Elias et al 2004 terhadap dua kelompok umur berbeda yaitu kelompok pertama dengan umur 18-46 tahun dan kelompok kedua pada umur 47-83 tahun, menyatakan bahwa tekanan darah tinggi berhubungan dengan penurunan fungsi kognitif baik pada dewasa muda maupun pada usia yang lebih tua. ${ }^{13}$

Terdapat beberapa cara atau tes neuropsikologis dalam mengetahui gangguan atau penurunan fungsi kognitif yaitu salah satunya dengan Mini Mental State Examination. Penggunaan MMSE dikenal lebih mudah dan praktis dalam pemeriksaan neuropsikologis pasien dan paling sering digunakan dalam tes fungsi kognitif seseorang dengan reliabilitas dan validitas yang cukup baik. ${ }^{14}$

Sangat penting untuk mengantisipasi dan melakukan berbagai pencegahan terhadap berbagai faktor risiko terjadinya MCI, sehingga peneliti tertarik untuk mengetahui hubungan MCI dengan salah satu faktor risikonya yaitu hipertensi.Diharapkan dengan penelitian ini dapat membantu pencegahan terhadap MCI, sehingga kualitas hidup yang lebih baik bisa didapatkan.

Belum terdapat informasi yang jelas tentang kejadian MCI di Pekanbaru. Prevalensi hipertensi sebagai salah satu faktor resiko MCI menurut profil kesehatan provinsi Riau tahun 2010 yang dilakukan dibeberapa puskesmas terpilih, terdapat bahwa penderita hipertensi di Pekanbaru pada perempuan lebih banyak daripada laki-laki. ${ }^{12}$

Kelompok ibu Pembinaaan Keluarga Sejahtera RW IX Kelurahan Tangkerang Timur merupakan kelompok organisasi kemasyarakatan yang aktif melakukan berbagai kegiatan terutama dibidang kesehatan. Berdasarkan survey yang telah dilakukan, ibu PKK di RW IX Kelurahan Tangkerang Timur Pekanbaru rata-rata memiliki indeks massa tubuh (IMT) yang obesitas dan tekanan darah yang tinggi. Sehingga kemungkinan untuk terjadinya MCI cukup besar. Pencegahan lebih dini sangat diperlukan untuk meningkatkan kesejahteraan hidup terutama pada ibu yang menjadi pusat keluarga, sehingga peneliti tertarik untuk melakukan penelitian di wilayah tersebut.

\section{METODE PENELITIAN}

Penelitian ini merupakan penelitian analitik dengan metode cross-sectional yang bertujuan untuk mengidentifikasi hubungan MCI dengan hipertensi menggunakan MMSE pada ibu PKK RW IX Kelurahan Tangkerang Timur Pekanbaru. Penelitian ini telah dilaksanakan pada bulan januari 2015. Populasi pada penelitian ini adalah ibu PKK RW IX Kelurahan Tangkerang Timur. Sampel pada penelitian ini adalah bagian dari populasi yang memenuhi kriteria inklusi. Pengambilan sampel dengan menggunakan metode total sampling, dimana seluruh populasi dijadikan sampel.

Mild cognitive impairment dinilai dengan melakukan pemeriksaan fungsi kognitif dengan lembar MMSE. Data dianalisis secara statistik dengan menggunakanchi-square $(\mathrm{p}=<0,05)$.

\section{HASIL PENELITIAN}

Penelitian ini dilakukan pada ibu PKK di RW IX Kelurahan Tangkerang Timur Pekanbaru dengan karakteristik subjek seperti yang tertera di tabel 1 . Jumlah subjek yang terlibat dalam penelitian ini adalah 50 orang.

Tabel 1. Data karakteristik subjek $(\mathrm{N}=50)$

\begin{tabular}{lcc}
\hline Karakteristik subjek & \multicolumn{2}{c}{ Jumlah } \\
\cline { 2 - 3 } & $\mathrm{N}$ & $\%$ \\
\hline Kelompok usia & & 56 \\
$23-48$ & 28 & 44 \\
$49-74$ & 22 & \\
Pendidikan & & 22 \\
$\quad$ Rendah & 11 & 74 \\
$\quad$ Menengah & 37 & 4 \\
Tinggi & 2 & \\
\hline
\end{tabular}


Berdasarkan tabel 1 dapat dilihat bahwa dari 50 subjek penelitian, berdasarkan kelompok usia, jumlah subjek lebih banyak di usia 23-48 tahun yaitu 28 orang (56\%) dan usia 49-74 tahun berjumlah 22 orang (44\%). Menurut tingkat pendidikan, responden yang berpendidikan menengah lebih banyak yaitu 37 orang (74\%).

\section{Angka kejadian mild cognitive impairment pada ibu PKK RW IX Kelurahan Tangkerang Timur}

Responden yang terlibat dalam penelitian ini sebelumnya dianamnesis terlebih dahulu untuk mengetahui riwayat penyakit saraf atau kemungkinan kecacatan yang memungkinkan mengganggu proses penelitian sehingga dapat dipastikan data MCI ini benar-benar valid. Hasil pemeriksaan MCI pada ibu PKK RW IX ini menggunakan lembar MMSE yang umum digunakan dalam penilaian fungsi kognitif. Angka kejadian MCI pada ibu PKK RW IX Kelurahan Tangkerang Timur Pekanbaru yang diteliti oleh peneliti dapat dilihat pada tabel 2.

Tabel 2. Angka kejadian mild cognitive impairment pada ibu PKK RW IX Kelurahan Tangkerang Timur Pekanbaru $(\mathrm{N}=50)$

\begin{tabular}{lcc}
\hline \multicolumn{1}{c}{ Angka kejadian mild cognitive impairment } & $\mathbf{N}$ & $\mathbf{\%}$ \\
\hline Mild cognitive impairment & 31 & 62 \\
Normal & 19 & 38 \\
\hline Total & 50 & 100 \\
\hline
\end{tabular}

Berdasarkan tabel 2 dari 50 responden diketahui terdapat sebanyak 31 responden (62\%) yang mengalami MCI dan yang bukan MCI sebanyak 19 responden (38\%).

Tabel 3. Data distribusi responden berdasarkan pemeriksaan MMSE (N=50)

\begin{tabular}{lcccc}
\hline Karakteristik & \multicolumn{2}{c}{ MCI } & Normal \\
\cline { 2 - 5 } & $\mathrm{N}$ & $\%$ & $\mathrm{~N}$ & $\%$ \\
\hline Usia & 12 & 24 & 16 & 32 \\
23-48 tahun & 19 & 38 & 3 & 6 \\
49-74 tahun & & & & \\
Pendidikan & 11 & 22 & 0 & 0 \\
Rendah & 20 & 40 & 17 & 34 \\
Menengah & 0 & 0 & 2 & 4 \\
Tinggi & & & & \\
\hline
\end{tabular}

Berdasarkan tabel 3 dapat dilihat bahwa dari 50subjek penelitian, berdasarkan kelompok usia, kejadian MCI lebih banyak pada usia 49-74 tahun yaitu 19 orang (38\%). Selain itu, dilihat dari karakteristik pendidikan responden yang mengalami MCI lebih banyak pada yang pendidikan menengah 20 orang (40\%).

\section{Angka kejadian hipertensi pada ibu PKK RW IX Kelurahan Tangkerang Timur}

Pengukuran tekanan darah dilakukan dengan menggunakan spygnomanometer dan stetoskop. Responden terlebih dahulu diistirahatkan 5 menit apabila baru saja melakukan kegiatan berat dan dilakukan anamnesis apakah pernah mengalami hipertensi untuk mengetahui kemungkinan tekanan 
darah yang akan diperiksa. Angka kejadian hipertensi pada ibu PKK RW IX Kelurahan
Tangkerang Timur Pekanbaru dapat dilihat pada tabel 4 .

Tabel 4. Angka kejadian hipertensi pada ibu PKK RW IX Kelurahan Tangkerang Timur Pekanbaru (N=50)

\begin{tabular}{lccc}
\hline & Angka kejadian hipertensi & $\mathbf{N}$ & $\mathbf{\%}$ \\
\hline Hipertensi & 26 & 52 \\
Normal & 24 & 48 \\
\hline Total & 50 & 100 \\
\hline
\end{tabular}

Berdasarkan tabel 4.dari 50 responden diketahui terdapat sebanyak 26 orang (52\%) yang mengalami hipertensi dan yang normal sebanyak 24 orang (48\%).

Tabel 5. Data distribusi berdasarkan pemeriksaan tekanan darah

\begin{tabular}{ccccc}
\hline \multirow{2}{*}{ Karakteristik } & \multicolumn{2}{c}{ Hipertensi } & $\mathrm{N}$ & Normal \\
\cline { 2 - 5 } & $\mathrm{N}$ & $\%$ & 20 & 40 \\
\hline Usia & 8 & 16 & 4 & 8 \\
23-48 tahun & 18 & 36 & 2 & 4 \\
49-74 tahun & & & 20 & 40 \\
Pendidikan & 9 & 18 & 2 & 4 \\
Rendah & 17 & 34 & & \\
Menengah & 0 & 0 & & \\
Tinggi & &
\end{tabular}

Berdasarkan tabel 5, dapat dilihat bahwa dari 50 subjek penelitian, berdasarkan kelompok usia, kejadian hipertensi lebih banyak pada usia 49-74 tahun yaitu 18 orang (36\%). Selain itu, dilihat dari karakteristik pendidikan responden kejadian hipertensi lebih banyak pada yang berpendidikan menengah yaitu 17 orang (34\%).
Hubungan mild cognitive impairment dengan hipertensi pada ibu PKK RW IX Kelurahan Tangkerang Timur

Hasil uji statistik mengenai hubungan mild cognitive impairment dengan kejadian hipertensi dapat dilihat pada tabel 6 .

Tabel 6. Hubungan mild cognitive impairment dengan kejadian hipertensi pada ibu PKK RW IX Kelurahan Tangkerang Timur Pekanbaru (N=50)

\begin{tabular}{lccccccc}
\hline \multirow{2}{*}{$\begin{array}{l}\text { Mild Cognitive } \\
\text { Impairment }\end{array}$} & \multicolumn{4}{c}{ Tekanan darah } & Jumlah & P value \\
\cline { 2 - 8 } & $\mathbf{N}$ & $\mathbf{\%}$ & $\mathbf{N}$ & $\mathbf{\%}$ & $\mathbf{N}$ & $\mathbf{\%}$ & \\
\hline MCI & 21 & 42 & 10 & 20 & 31 & 62 & 0,004 \\
Normal & 5 & 10 & 14 & 28 & 19 & 38 & \\
\hline Jumlah & 26 & 52 & 24 & 48 & 50 & 100 & \\
\hline
\end{tabular}


Berdasarkan tabel 6. diketahui dari 31 orang yang mengalami MCI ditemukan 21 responden (42\%) yang mengalami hipertensi. Hasil uji statistik dengan menggunakan uji Chi Square didapatkan nilai p sebesar 0,004 $(<0,05)$. Hal ini menunjukkan terdapat hubungan yang bermakna antara MCI dengan kejadian hipertensi pada ibu PKK RW IX Kelurahan Tangkerang Timur Pekanbaru.

\section{PEMBAHASAN}

Penelitian untuk mengetahui hubungan MCI dengan hipertensi menggunakan MMSE telah dilakukan. Jumlah responden yang dilibatkan pada penelitian ini adalah 50 orang ibu PKK RW IX Kelurahan Tangkerang Timur Pekanbaru menggunakan metode total sampling.

\section{Angka kejadian mild cognitive impairment pada ibu PKK RW IX Kelurahan Tangkerang Timur Pekanbaru}

Hasil pemeriksaan pada penelitian ini dikelompokkan sebagai MCI (skor MMSE 21-26) dan bukan MCI atau normal (skor MMSE 27-30). Berdasarkan hasil penelitian yang telah dilakukan dari 50 orang responden, yang mengalami MCI sebanyak 31 orang (62\%) dan bukan MCI sebanyak19 orang (38\%). Penelitian ini hampir serupa dengan penelitian yang dilakukan oleh Abadi $\mathrm{K}$ et al mendapatkan dari 32 orang terdapat 21 orang (65,6\%) yang mengalami MCI. ${ }^{5}$

Berdasarkan usia responden, dengan usia paling muda adalah 23 tahun dan usia paling tua adalah 74 tahun dengan nilai tengah usia yaitu 48 tahun. Hasil penelitian menunjukkan dari 28 orang dengan usia 23-48 tahun terdapat sebanyak 12 orang (42,85\%) yang mengalami MCI dan 16 orang (57,15\%) diantaranya normal. Pada kelompok usia 49-74 tahun dari 22 orang terdapat sebanyak 19 orang (86,36\%) yang mengalami MCI dan 3 orang $(13,64 \%)$ diantaranya normal. Hasil penelitian ini menunjukkan bahwa usia seseorang mempengaruhi kognitifnya, dimana pada kelompok usia tua memiliki kejadian MCI yang lebih banyak daripada kelompok usia yang lebih muda. Hasil ini sejalan dengan penelitian lain yang dilakukan oleh Ratnasari D tahun 2010 juga menunjukkan bahwa semakin tinggi usia seseorang, fungsi kognitif pun semakin mengalami penurunan. ${ }^{33}$ Usia memang menjadi salah satu faktor utama terjadinya MCI atau penurunan fungsi kognitif, banyak teori yang menyatakan bahwa semakin tinggi usia seseorang maka kemampuan kognitif seperti mengingat, berfikir, dan memahami bahasa akan semakin berkurang pula. ${ }^{16}$ Mild cognitive impairment ini dikatakan sebagai fase predemensia atau transisi antara demensia dan alzheimer. Alzheimer disease menjadi faktor resiko yang sangat berbahaya bagi seseorang yang mengalami MCI, karena seseorang dengan MCI 10-15\% akan menjadi alzheimer. ${ }^{2,3,17,21}$

Berdasarkan tingkat pendidikan responden, dari 11 orang dengan tingkat pendidikan rendah yang mengalami MCI sebanyak 11 orang (100\%) atau seluruhnya mengalami MCI. Responden dengan tingkat pendidikan menengah dari 37 orang terdapat 20 orang $(54,05 \%)$ diantaranya yang mengalami MCI dan 17 orang (45,95\%) yang bukan MCI dan dari 2 orang responden yang memiliki tingkat pendidikan tinggi, tidak ada yang mengalami MCI. Berdasarkan hasil penelitian ini menunjukkan bahwa pendidikan seseorang mempengaruhi kemampuan kognitifnya. Semakin rendah tingkat pendidikan maka semakin rendah pula kemampuan kognitifnya. Hal ini sejalan dengan penelitian yang dilakukan oleh Ramadian DA et al dengan hasil penelitian bahwa tingkat pendidikan yang rendah mempengaruhi fungsi kognitif seseorang. ${ }^{34}$ Penelitian yang dilakukan oleh Razali R et al juga menunjukkan hasil yang sama bahwa kognitif dapat dipengaruhi dengan tingkat pendidikan orang tersebut. ${ }^{16}$ Hasil penelitian ini menunjukkan bahwa aktivitas intelectual dapat melawan gangguan kognitif dengan memperkaya ilmu seiring berjalannya waktu maka akan mengurangi gangguan kognitif termasuk demensia. ${ }^{36}$

\section{Angka kejadian hipertensi pada ibu PKK RW IX Kelurahan Tangkerang Timur Pekanbaru}

Hasil penelitian ini dibagi menjadi hipertensi dengan tekanan darah $\geq 140 / \geq 90 \mathrm{mmHg}$ dan normal dengan tekanan darah $<140 /<90 \mathrm{mmHg}$. Berdasarkan penelitian yang telah dilakukan pada 50 orang responden, terdapat 26 orang (52\%) yang mengalami hipertensi dan 24 orang (48\%) yang normal. 
Berdasarkan usia responden, hasil penelitian menunjukkan dari 28 orang dengan usia 23-48 tahun terdapat sebanyak 8 orang $(28,57 \%)$ dengan hipertensi dan 20 orang $(71,43 \%)$ diantaranya normal, sedangkan pada kelompok usia 49-74 tahun dari 22 orang responden terdapat sebanyak 18 orang (81,82\%) dengan hipertensi dan 4 orang $(18,18 \%)$ diantaranya normal. Hasil penelitian ini juga menunjukkan bahwa dari 26 orang responden dengan hipertensi, kejadian hipertensi lebih banyak pada kelompok usia 49-74 tahun, yaitu 18 orang. Hal ini menunjukkan bahwa semakin tinggi usia seseorang maka resiko terjadinya hipertensi juga semakin meningkat. Sejalan dengan penelitian lain yang dilakukan oleh Sari IPF et al bahwa kelompok usia yang lebih tua menunjukkan kejadian hipertensi yang semakin tinggi. ${ }^{35}$ Usia ini menjadi salah satu faktor resiko terjadinya hipertensi, terutama umur lebih dari 40 tahun mempunyai resiko tinggi terjadinya hipertensi. Seiring dengan bertambahnya usia, arteri menjadi kehilangan elastisitasnya atau kelenturannya dan tekanan darah menjadi meningkat. ${ }^{37}$

Berdasarkan tingkat pendidikan, hasil penelitian menunjukkan dari 11 orang dengan pendidikan rendah 9 orang $(81,81 \%)$ mengalami hipertensi dan 2 orang (18,19\%) lainnya normal. Responden dengan tingkat pendidikan menengah dari 37 orang terdapat 17 orang (45,94\%) diantaranya mengalami hipertensi dan 20 orang (54,06\%) tidak mengalami hipertensi dan dari 2 orang responden yang memiliki tingkat pendidikan tinggi, tidak ada yang mengalami hipertensi. Bedasarkan hasil penelitian ini menunjukkan bahwa semakin rendah pendidikan seseorang maka semakin tinggi pula kejadian hipertensi.

\section{Hubungan mild cognitive impairment dengan hipertensi menggunakan MMSE pada ibu PKK RW IX Kelurahan Tangkerang Timur Pekanbaru}

Berdasarkan analisa statistik yang telah dilakukan untuk mengetahui hubungan mild cognitive impairment dengan hipertensi pada ibu PKK RW IX Kelurahan Tangkerang Timur Pekanbaru, ditemukan hubungan yang bermakna antara mild cognitive impairment dengan hipertensi dengan uji chi-square dengan nilai $\mathrm{p}=0,004(\mathrm{p}<0,05)$.
Hasil penelitian ini sejalan dengan penelitianpenelitian lain yang telah dilakukan, seperti penelitian yang dilakukan oleh Abadi $\mathrm{K}$ et alyang memiliki hasil hubungan bermakna antara MCI dengan hipertensi. ${ }^{5}$ Penelitian oleh Zhao Y et al juga menunjukkan hasil yang hampir serupa ${ }^{38}$ Penelitian oleh Kilander L et al juga menunjukkan hubungan antara MCI dengan hipertensi. ${ }^{39}$ Penelitian lain oleh Christiane Reitz et al juga menunjukkan hubungan bermakna antara MCI dengan hipertensi. ${ }^{7}$

Hal ini terjadi karena hipertensi merupakan salah satu faktor risiko mild cognitive impairment, walaupun tidak memiliki proses langsung antara hipertensi dengan gangguan kognitif namun hipertensi sering dihubungkan dengan gangguan fungsi kognitif. Peningkatan tekanan darah memicu timbulnya lesi di area putih subkortikal otak. Hipertensi juga menimbulkan aterosklerosis, sehingga terjadi penebalan dinding arteri dan penurunan permeabilitas dinding pembuluh darah yang mengakibatkan meningkatnya transport lipoprotein ke dalam dinding arteri, meningkatnya proliferasi sel otot polos serta sintesis matriks molekul ekstra sel sehingga menyebabkan aliran darah ke otak menurun dan terbentuknya lesi pada jaringan otak akibat kerusakan endotel dan insufisiensi aliran darah serebral akibat iskemia pada arteri serebral otak. Pada akhirnya kondisi ini menyebabkan kerusakan jaringan otak seperti yang ditemukan pada mild cognitive impairment. Hubungan antara tekanan darah dengan penyakit alzheimer sebagai faktor resiko dari MCI menunjukkan peningkatan frekuensi dari neurofibrillary tangle dan atrofi otak pada orang dengan hipertensi. ${ }^{5,6}$

\section{SIMPULAN}

1. Kejadian MCI pada ibu PKK RW IX Kelurahan Tangkerang Timur cukup tinggi yaitu 31 orang (62\%).

2. Kejadian hipertensi pada ibu PKK RW IX KelurahanTangkerang Timur adalah 26 orang (52\%).

3. Terdapat hubungan yang bermakna antara MCI dengan kejadian hipertensi pada ibu PKK RW IX Kelurahan Tangkerang Timur Pekanbaru. 


\section{DAFTAR PUSTAKA}

1. Plassman LB. Langa KM. Fisher GG. Prevalence of cognitive impairment without dementia in the united states. National Institutes of Healt; 2008. 427-34.

2. Morris JC. Storandt M. Miller JP. Mckeel DW. Price JL. Rubin EH et al. Mild cognitive impairment represents early-stage alzheimer disease. Arch Neurol; 2001. 58: 397-405.

3. Medina D. Morrel LD. Urresta F. Gabrieli JDE. Moseley M. Fleischman D et al. White matter changes in mild cognitive impairment and AD:A diffusion tensor imaging study. Neurology of Aging; 2006. 27: 663-72.

4. Portet F. Ousset PJ. Visser PJ. Frisoni GB. Nobili F. Scheltens $\mathrm{P}$ et al. Mild cognitive impairment (MCI) in medical practice: a critical review of the concept and new diagnostic procedure. Report of the MCI Working Group of the European Consortium on Alzheimer's Disease. J Neurol Neurosurg Psychiatry; 2006. 77: 7148.

5. Abadi K. Wijayanti D. Gunawan EA. Rumawas ME. Sutrisna B. Hipertensi dan risiko mild cognitive impairment pada pasien usia lanjut. Jurnal Kesehatan Masyarakat Nasional; 2013. 8(3): 119-24.

6. Reitz C. Tang MX. Manly J. Mayeux R. Luchsinger JA. Hypertension and the risk of mild cognitive impairment. Arch Neurol; 2007. 64(12): 1734-40.

7. Suwa M. Cardiovascular and cerebrovascular problems in the development of cognitive impairment: for medical professionals involved in the treatment of atherosclerosis. The Cardiovascular System - Physiology, Diagnostics and Clinical Implications; 2012. 15: 311-8.

8. Sugiyanto E. Hipertensi dan komplikasi serebrovaskuler. Cermin Dunia Kedokteran; 2007. 157.

9. Gunawan G. Farmakologi dan terapi. Edisi 5. Jakarta. Badan Penerbit FKUI; 2007. 341-4.

10.Sudoyo AW. Setiyohadi B. Alwi I. Simadibrata KM. Setiati S. Buku ajar ilmu penyakit dalam. Jilid II. Edisi V. Jakarta. Interna publishing; 2009. 1079-82.
11.Badan penelitian dan pengembangan kesehatan kementerian kesehatan RI. Hasil riset kesehatan dasar 2013; 88.

12.Dinas Kesehatan Provinsi Riau. Profil kesehatan provinsi Riau. Pekanbaru; 2010.

13.Elias MF. Robbins MA. Schultz NR, Streeten DHP. Elias PK. Clinical Significance of Cognitive Performance by Hypertensive Patients. Journal of America Heart Association; 1987. 9: 192-197.

14.Folstein MF. Folstein SE. McHugh PR. Minimental state A practical method for grading the cognitive state of patients for the clinician. J Psychiatr Res; 1975.12:189-98.

15.Ratnasari D. Perbedaan fungsi skor kognitif stroke iskemik pertama dengan iskemik berulang dengan lesi hemisfer kiri. Universitas Sebelas Maret. Surakarta; 2010.

16. Razali R. Baharudin A. Jaafar NRN. Sidi H. Rosli AH. Hooi KB et al. Factors associated with mild cognitive impairment among elderly patients attending medical clinics in universiti kebangsaan malaysia medical centre. Sains Malaysiana; 2012. 41(5): 641-7.

17.Petersen RC. Smith GE. Waring SC. Ivnik RJ. Tangalos EG. Kokmen E. Mild cognitive impairment clinical characterization and outcome. Arch Neurol; 1999. 56: 303-8.

18.Beard RL. Neary TM. Making sense of nonsense: experiences of mild cognitive impairment. Sociology of Health \& Illness; 2013. 35(1): 13046.

19. Ramadian DA. Maja J. Runtuwene T. Gambaran fungsi kognitif lansia di tiga yayasan manula di kecamatan kawangkoan. Manado; 2012.

20.Chenderes RM. Podea DM. Nanu PD. Mila C. Mild cognitive impairment and intellectual activity in the elderly. Eur Psychiatry; 2009. 24: 1094

21.Sugiharto A. Faktor-faktor resiko hipertensi pada masyarakat (studi kasus di kabupaten karanganyar. Universitas Diponegoro. Semarang; 2007.

22.Zhao Y. Wu G. Shi H. Xia Z. Sun T. Relationship between cognitive impairment and apparent 
JIK, Jilid 9, Nomor 2, September 2015, Hal. 99-106

diffusion coefficient values from magnetic resonance-diffusion weighted imaging in elderly hypertensive patients. Clinical Interventions with Aging. Dovepress Journal; 2014.
23.Kilander L. Nyman H. Boberg M. Hansson L. Lithell $\mathrm{H}$. Hypertension is related to cognitive impairment. Aha journal; 1997 